\title{
MEMÓRIA E TRANSFORMAÇÃO SOCIAL: TRABALHADORES DE CIDADES INDUSTRIAIS*
}

José Sergio Leite Lopes

\section{Introdução}

As mudanças na organização do trabalho na indústria e na agroindústria têm provocado a tendência a uma diminuição drástica no número de trabalhadores empregados nestes setores. A assim chamada classe operária, anteriormente concebida como grupo social crescente, enquanto paralelamente os grupos estudados pelos primeiros antropólogos estariam em desaparecimento diante da expansão mundial do capitalismo, é vista por sua vez, um século depois, ela própria como classe social minguante. Talvez então possa ela ser incluída ironicamente como objeto legítimo da curiosidade antropológica clássica, agora que está envolvida em um processo de extinção de suas propriedades sociais características.

Alimentado pelo efeito-teoria de visões macrossociais que o projetavam como modelo da sociedade futura, o operariado parece, ao contrário, ter perdido recentemente sua morfologia social do grande número concentrado, que impressionava os observadores contemporâneos do seu surgimento como os irmãos Lumière, que dedicaram algumas das primeiras filmagens do seu novo invento ao registro do movimento massivo das saídas de fábrica. De símbolo de progresso, mudança e transformação social, os trabalhadores industriais passaram a ser objeto de memória. É bem verdade, por outro lado, que os antropólogos estão acostumados a desconfiar das previsões de desaparecimento de povos ou de grupos sociais. No caso presente, observase um conjunto de fenômenos em transformação, desde um deslocamento geográfico do trabalho fabril até a sua recriação com outras roupagens na agricultura e nos serviços.

Não somente os antropólogos, mas os trabalhadores - desde que em condições de preservar e transmitir entre suas gerações experiências passadas - poderão relativizar o ineditismo das previsões apocalípticas de precarização ou extinção do trabalho manual. Eles já viveram tais situações 
em outros períodos históricos. De fato a capacidade de transmissão da própria história entre as gerações de trabalhadores varia de grupo para grupo. Minha experiência de pesquisa baseou-se na comparação entre dois grupos sociais de trabalhadores do ponto de vista de sua relação com a história e a formação de uma memória coletiva. São eles: a) os operários industriais de usinas de açúcar no Nordeste; e b) os operários e as operárias têxteis, e suas famílias, em uma fábrica e em uma vila operária exemplar, em Pernambuco, como caso-limite das fábricas dos primeiros 70 anos da industrialização brasileira do século XX.

\section{Diferentes grupos sociais, diferentes historicidades}

Estes dois grupos estudados sucessivamente e comparados a posteriori apresentam uma relação diferenciada e mesmo polarizada em diferentes concepções de história. Os operários do açúcar apresentam a concepção de um tempo estrutural cíclico, alternado por administrações sucessivas. Devido à importância das relações constituídas no interior de tais administrações, ocorrem periodicamente migrações por equipes ou cliques no mercado de trabalho das usinas de açúcar. Um mestre ou chefe de seção que sai tende a levar seus homens de confiança para o emprego seguinte. Trata-se de uma história masculina, na qual a família operária se apresenta como pano de fundo, dependente dos trabalhadores masculinos, os pais de família. Tal concepção tem todas as aparências de uma "história fria", sobretudo se comparada com seus vizinhos de processo agroindustrial, os trabalhadores rurais situados na mesma área de plantation.

Os operários do açúcar, por serem considerados "industriais", foram beneficiados pela legislação nacional do trabalho implantada nos anos 1940, durante um período de governo ditatorial (o que, por sinal, contribuiu para quebrar a resistência patronal a essas medidas). Em contraste com os trabalhadores da parte rural da plantation, que constituíam a grande maioria excluída desses direitos, eles passaram a ocupar uma posição de superioridade relativa na hierarquia das usinas. Ao contrário, os trabalhadores rurais, moradores e depois trabalhadores de rua, também conhecidos como clandestinos, tiveram acesso aos direitos trabalhistas vinte anos depois dos operários, em pleno período democrático e de forte mobilização social. Estes foram, logo depois, o alvo principal, na área canavieira, da repressão por parte da nova ditadura implantada pelos militares em 1964.

O processo então desencadeado, a partir da inclusão tardia dos trabalhadores rurais aos direitos sociais e da subsequente expulsão dos moradores por parte dos proprietários, proporcionou a estes trabalhadores a comparação entre 
um passado idealizado, de acesso a concessões anexas à moradia e a relações personalizadas com alguns patrões, e um presente de dificuldades maiores. O instrumental cognitivo proporcionado por essa visão do passado, aliado à curta vivência no início dos anos 60 de um sentimento de libertação, dava a este grupo social a possibilidade e a vontade de associação reivindicativa mesmo sob condições severas de repressão. Enquanto isso, os operários do açúcar guardavam distância do momento de entrada dos direitos nos anos 40 sem a mesma mobilização dos camponeses e dos trabalhadores rurais vinte anos depois. No período repressivo pós-64 não dispunham dos mesmos instrumentos associativos e resistiam a uma exploração cotidiana do trabalho de forma atomizada.

Já os operários e as operárias têxteis da grande companhia industrial que criou uma cidade no início do século XX apresentavam uma alta sensibilidade quanto à apropriação singular de acontecimentos internos e externos que traziam consequências sobre a vida social local. A trajetória do campo para a fábrica, comum à grande maioria destes trabalhadores, a grandeza e o carisma patronais, a luta pelo cumprimento dos direitos desde os anos 1940, as greves dos anos 50 e início dos 60 e o movimento contra a opressão aos operários estáveis entre os anos de 1967 até o início dos anos 80 são todos fatores de elaboração de uma historicidade "quente". Por sinal, comparável à sensação "térmica-social" não dos operários industriais do açúcar, mas à dos trabalhadores rurais canavieiros dos anos 60 e 80 .

\section{Os operários na literatura antropológica}

O que havia de disponível na literatura para se tratar de forma antropológica os operários industriais no momento em que essas pesquisas foram feitas? Como a minha pesquisa inicial se deu no interior de um projeto coletivo visando estudar a plantation canavieira, partíamos do conhecimento dos estudos de Eric Wolf e Sidney Mintz no Caribe, dentro da tradição da antropologia cultural norte-americana. O tema da proletarização aparecia nos estudos sobre campesinato e sociedades camponesas. Também estava presente nas pesquisas de Pierre Bourdieu do início dos anos 60 sobre o campesinato e os trabalhadores urbanos argelinos. E se encontrava nos capítulos de análise histórica ancorada em material empírico do Livro 1 de O Capital, de Karl Marx. Também se dispunha do conhecimento de resultados das pesquisas de antropologia urbana que faziam parte dos estudos de sociologia e antropologia da chamada segunda geração da escola de Chicago, como a análise interacionista das instituições totais de Ervin Goffman. E, finalmente, se dispunha do instrumental criado para o estudo 
de sociedades "tribais" ("simples", "indígenas" etc.), como as classificações coletivas de Mauss e Durkheim, o pensamento selvagem de Lévi-Strauss, o tempo estrutural de Evans-Pritchard, a serem apropriados para o contexto agroindustrial e fabril pesquisado.

Também se colocava a questão do acesso ao campo, da entrada nos domínios da empresa que incluíam não só a fábrica como a moradia dos seus trabalhadores. Quando desta tematização na entrada do Vapor do Diabo, em 1975, contava-se com as reflexões de Simone Weil sobre sua experiência operária dos anos 30, na França. Mas ainda não da descrição e da análise de Robert Linhart como établi, termo que significa o militante político implantado na fábrica, no caso, na Citroën de Paris, que só foi publicada em 1978. E eu mal conhecia a experiência de Donald Roy como pesquisadorenquanto-operário, nos anos 40, em Chicago, orientando de Everett Hugues, que recentemente tem sido revalorizada. Roy havia sido colega de turma de Howard S. Becker. Não se tratava para mim, na ocasião, de trabalhar como operário para fazer assim observação participante. Naquele momento, em 1972, os établis locais (como o Betinho) estavam sendo procurados pelo DOI-CODI. Era o caso simplesmente de ter acesso aos trabalhadores com a possibilidade de estabelecer as relações de confiança necessárias para a pesquisa etnográfica. ( $\mathrm{Na}$ época se conhecia também a experiência de Richard Hoggart, mas dele se falará mais adiante).

Assim, em meados dos anos 70, eu pensava estar entrando em um território inexplorado pela antropologia, aquele ocupado pelas condições de trabalho e de vida dos operários. De fato, só depois fui buscar antecedentes de um enfoque antropológico em estudiosos universitários ou não universitários sobre as classes trabalhadoras, inclusive o dos antropólogos profissionais. Em parte os operários haviam sido encontrados pelos etnógrafos em algum lugar no meio do folk-urbano formulado pelos antropólogos culturais norte-americanos. Foram, assim, desde os trabalhadores têxteis indígenas da localidade de Cantel, na Guatemala, estudados por Manning Nash (com a colaboração de June Nash) nos anos 1950, até os operários de Yankee City descritos por Lloyd Warner, ou os metalúrgicos de Chicago, aos quais se incorporou como nativo e pesquisador não declarado Donald Roy.

A proximidade da antropologia e da sociologia na tradição da escola de Chicago fez com que antropólogos como Warner e Foote-Whyte transitassem de estudos de temas clássicos da disciplina antropológica (no caso do primeiro) e de comunidades étnicas urbanas (no caso do último) para estudos assemelhados à sociologia industrial, embora fortemente instrumentalizados pela etnografia. Algumas universidades norte-americanas fundaram nos anos 1940 institutos de relações humanas associados às indústrias, onde se 
incluíam projetos de antropologia aplicada, geralmente reformadores, em torno do tema de "relações industriais". Este fato não deixa de ter relação com o que era ensinado na Escola Livre de Sociologia e Política de São Paulo, com a presença de Donald Pierson, ao lado de disciplinas de administração e relações industriais, e com a posterior entrada do antropólogo Mario Wagner Vieira da Cunha na primeira direção do Instituto de Economia e Administração da USP e do recrutamento para lá do jovem Juarez Brandão Lopes. Mas este é assunto para outra ocasião.

No caso de outros centros mundiais das ciências sociais, como a França e a Inglaterra, a espera pelo retorno à casa da antropologia (Anthropology at Home) à primeira vista parecia ser necessária para que os antropólogos se interessassem pelos trabalhadores em suas próprias cidades industriais. $\mathrm{Na}$ Inglaterra houve precursores, como o estudo de Raymond Firth sobre família no bairro proletário do East End de Londres (Two studies of kinship in London), ou as famílias e as redes sociais de Elisabeth Bott, que incluíam famílias de trabalhadores. Havia os estudos de comunidade depois sistematizados por Ronald Frankenberg. Entre estes estavam o de Dennis, Henriques e Slaughter (Coal is our life) e o de Young e Wilmott (Family and Kinship in East London). Por sinal, os autores de Coal is our life agradecem fortemente a orientação de Meyer Fortes e Max Gluckman. Também os estudos das cidades mineiras no Copperbelt da Rodésia do Norte fazem com que os antropólogos da escola de Manchester, atraídos pelas transformações nos comportamentos tribais nas cidades, se encontrem com trabalhadores industriais.

É interessante também a trajetória da antropóloga norte-americana Hortence Powdermaker, que circulou com desenvoltura entre as tradições da disciplina acadêmica de seu país e da Grã-Bretanha, assim como se moveu entre temas clássicos e heterodoxos. Fez tese, sob orientação de Malinowski, na LSE, em Lesu, na Melanésia, indo em seguida estudar relações raciais no Mississipi, respaldada por Sapir. Depois foi etnografar Hollywood após ter observado o lugar da recepção do cinema no sul dos EUA. E, finalmente estudou os mineiros africanos na sua monografia Copper Town, no Copperbelt da Rodésia do Norte. Tudo isso após um ímpeto de juventude que a levou da graduação universitária em História ao trabalho de ativismo sindical no setor de confecções em seu país.

\section{A hipótese da tradição transformadora}

Mas estas são considerações a posteriori de que eu não dispunha no momento de começar a fazer a segunda pesquisa com operários e operárias têxteis em 
Pernambuco, na busca por uma espécie de plantation estendida à cidade e ao subúrbio nas particularidades das vilas operárias industriais. O que de fato fui lendo no entremeio das primeiras idas ao campo foi o livro de E.P. Thompson, The Making of the English Working-Class, publicado em 1963, e reeditado pela Penguin em 1968. Ali aparecia de forma clara, com base na experiência da revolução industrial inglesa, a hipótese da importância do passado, da memória, da história incorporada para a possibilidade de criação do novo.

Ao contrário de se ver no novo proletário industrial, o criador do movimento operário, Thompson mostrava através de farta documentação a importância de artesãos, trabalhadores a domicílio e trabalhadores rurais, destituídos pelas transformações capitalistas, como os motores ativos do novo movimento. Seriam estes, que têm um quadro de referência anterior dado por suas tradições de trabalho e de vida, por sua cultura, por sua religião - os que teriam condições de enfrentar os novos modos de dominação social em gestação. Era algo assemelhado a isto que eu e a colega Rosilene Alvim estávamos encontrando na cidade de Paulista, na Grande Recife. O predomínio da história do grupo operário sobre sua vida presente no relato espontâneo dos trabalhadores entrevistados; a ambiguidade entre as realizações de grandeza da empresa que se refletiam nas condições de vida e na experiência dos trabalhadores; e ao mesmo tempo o orgulho pela participação em protestos contra a ilegitimidade da dominação patronal.

Ao declarar que: "a experiência de classe é determinada em grande medida pelas relações de produção em que os homens nasceram", [mas o que nos interessa aqui] "é a forma como essas experiências são tratadas em termos culturais: encarnadas em tradições, sistemas de valores, ideias e formas institucionais", E.P. Thompson, no verdadeiro prefácio-manifesto do seu livro The Making of the English Working-Class, invertia o senso comum, inclusive o acadêmico, ao atribuir o protagonismo não ao polo moderno da transformação capitalista, a fábrica e seus operários, mas àqueles aos quais tais mudanças estavam deslocando e destruindo. Eram eles: os artesãos, os trabalhadores rurais e os camponeses, os trabalhadores a domicílio. Com isto, ele estava reforçando a recuperação de processos históricos cuja explicação se unia ao que estava acontecendo com a expropriação das sociedades camponesas e dos grupos artesanais na contemporaneidade da segunda metade do século XX. Também a microrresistência surda que existia no interior dos chãos de fábrica era assim valorizada — com os operários sendo destituídos constantemente de formas anteriores de produzir e de costumes e cargas de trabalho, o que acarretava o aumento crescente de seu esforço sub-remunerado. 
Isto de fato tinha a ver com o que havíamos observado na área canavieira do Nordeste. Como a memória da figura tradicional do morador estava sendo reforçada no momento mesmo em que ela tendia a desaparecer - como aparece na construção retrospectiva de seu tipo-ideal no artigo "Casa e Trabalho" ou "Morar", de Moacir Palmeira. Ou ainda na adição aparentemente paradoxal dos antigos costumes personalizados e "paternalistas" da relação tradicional de morada com os novos direitos alcançados em 1963 e então já ameaçados, efetuados pelos trabalhadores canavieiros - como analisado por Lygia Sigaud. Ou como a tradição das "artes industriais", ostentadas pelos artistas das seções de manutenção das usinas de açúcar, fornecia uma linguagem legítima para a reivindicação dos direitos de todos os operários, que eu pude perceber no Vapor do Diabo, graças ao trabalho anterior de Rosilene Alvim sobre os ourives. Ou ainda a ambiguidade dos operários têxteis, que se manifesta na soma de argumentos aparentemente contraditórios para efetuar a crítica à situação contemporânea da relação entre empresas e trabalhadores, através de relatos que registramos na segunda metade dos anos 1970, em Paulista, Pernambuco. Por um lado, são ressaltados os aspectos positivos selecionados que tinham as suas relações com os patrões na cidade industrial dos anos de 1930 e 1940. Por outro, também é narrada a grandeza da luta pela aplicação dos novos direitos sociais apropriados pela associatividade operária. De fato, mais do que uma aparente incoerência lógica na soma heterogênea de práticas "tradicionais" e "racionais-modernas", os trabalhadores operavam na lógica do fluxo contínuo e do tênue limite das apropriações dos usos das concessões e dos direitos. Como formula E.P. Thompson para o contexto diverso dos trabalhadores que vivem o início da revolução industrial inglesa, no livro Costumes em Comum:

Minha tese é a de que a consciência dos usos costumeiros era especialmente robusta no séc. XVIII. De fato, alguns "costumes" foram de invenção recente, e na verdade eram reivindicações de novos "direitos". O costume constituía a retórica de legitimação de quase todo uso, prática ou direito reclamado. Por isso o costume não codificado - e até mesmo o codificado - estava em fluxo contínuo. Longe de exibir a permanência sugerida pela palavra tradição, o costume era um campo para a mudança e a disputa, uma arena na qual interesses opostos apresentavam reivindicações conflitantes.

Assim, apesar de grande parte do operariado têxtil de Paulista guardar a imagem positiva da memória dos tempos em que a personalização patronal era exercida localmente, desde que os direitos sociais se instalaram e se tornaram disponíveis, no pós-guerra de 1945, disseminou-se rapidamente 
a prática da inscrição de reclamações na Justiça do Trabalho através do sindicato. Apesar de poderem ser vistos os trabalhadores brasileiros sob a aparência de estarem "afogados em leis", na expressão do historiador John D. French diante do tamanho da CLT, as leis servem de instrumento de negociação pelos trabalhadores diante da face autoritária dos costumes do patronato no trato com sua mão de obra. A apropriação das novas leis pelos trabalhadores se dá enquadrada pelo entendimento das suas relações anteriores com o patronato.

Este argumento thompsoniano do peso do passado nas disposições presentes dos trabalhadores, da importância de sua experiência, pode vir assim ao encontro do que está pressuposto no processo de atualização de um habitus de grupo (ou de uma história incorporada) tal como formulado de forma mais geral por Bourdieu. A hipótese de Thompson se dá na própria origem da revolução industrial, o que faz dotar seu argumento de uma generalidade maior que o simples caso, já que está ele presente paradoxalmente no evento associado à modernidade econômica capitalista ela mesma. Argumento semelhante encontra-se reeditado no caso da Alemanha, examinado por Barrington Moore Jr. em seu livro Injustiça. O autor mostra que, comparados aos metalúrgicos recém-surgidos no início do século XX na região do vale do rio Rhur, os mineiros da mesma região, cujas tradições remontavam ao período anterior à revolução industrial, possuíam padrões de legitimidade constituídos no passado do processo de trabalho da corporação artesanal em que estavam inseridos para condenar a intensificação do trabalho no presente.

Já aos metalúrgicos reunidos nas novas siderúrgicas da região faltavam tais padrões de legitimidade enraizados no passado para lhes fornecerem um instrumental de resistência às suas condições de exploração. Os mineiros do vale do Ruhr obtiveram assim, no início do século XX, um sucesso maior nas suas lutas e reivindicações. Também o historiador norte-americano William Sewell Jr., que foi aluno de Geertz, reforça esta argumentação ao focalizar o peso que tem o idioma artesanal corporativo dos trabalhadores franceses durante as revoluções de 1830 e 1848, apesar do anátema da grande revolução de 1789 sobre as instituições do antigo regime monárquico. Este também é um caso estratégico para o argumento thompsoniano, na medida em que ele pode se verificar mesmo no caso francês, atravessado pela revolução de 1789. Aqui um historiador não francês tem a vantagem de liberar-se das divisões entre períodos consagrados em que se especializam os profissionais da História, ao estudar ao mesmo tempo o fim do antigo regime e o período pós-revolução, e assim observar a continuidade do idioma corporativo na constituição de um discurso socialista que passa a se opor ao das novas classes dirigentes. 
Posteriormente a essas revoluções, o republicano Durkheim vem frisar a necessidade de reforçar o idioma e a prática profissional-corporativo-sindical diante das potencialidades de anomia provocadas pela moderna divisão do trabalho. E se os artesãos e os camponeses são vistos por E.P. Thompson como personagens ativos na revolução industrial capitalista com a qual se defrontam entre o fim do séc. XVIII e o início do XIX, também é nesse mesmo período que se desenrola, na Polinésia, o drama entre os ingleses e os havaianos, em que morre o Capitão Cook. Através da explicação desta morte, Marshall Sahlins mostra, na contracorrente, quão ativas podem ser as vítimas do assim chamado Sistema Mundial Capitalista, acionando suas tradições e seus habitus para se reapropriarem criativamente das trocas oferecidas por seus futuros conquistadores.

Não somente os historiadores sociais e culturais têm contribuído para problematizar a relação aparentemente paradoxal entre memória, tradição e transformação social, mas também outros especialistas provenientes de estudos sobre a recepção social da produção literária. Aparece aqui a figura de Richard Hoggart, professor de literatura inglesa que se debruçou sobre os usos populares do letramento (The uses of literacy) no final dos anos 1950, através das transformações e das repercussões de publicações de massa, como revistas de bancas de jornal sobre o público leitor das classes populares. Para isso, Hoggart fez primeiro uma caracterização do que seria a cultura das classes trabalhadoras inglesas, no interior das quais ele viveu na primeira metade do século XX. Desta forma, ele realizou uma etnografia utilizando-se da observação direta no momento que antecedeu à sua escritura do texto. Mas o fez também através da recuperação sistemática de sua memória como criança e jovem de uma família operária da região industrial de Leeds.

Esta etnografia retrospectiva de Hoggart abre espaço para outra forma de observação direta das classes trabalhadoras. Menos a observação direta do pesquisador, acadêmico ou não, que se coloca na pele do trabalhador diante da máquina no interior da fábrica, durante um período de tempo, como Simone Weil, Robert Linhart, Donald Roy ou Michael Burawoy, e mais a observação da vida cotidiana e do código interno do grupo diante da vida social, tal como o universitário egresso das classes trabalhadoras pode fazer em certas condições de revalorização cognitiva de sua experiência familiar de origem. Diante da avassaladora produção do entretenimento de massa dirigida às classes populares, que parece transferir sua baixa qualidade ao que seria a baixa qualidade de recepção do público, o autor pode opor a menos conhecida resistência desse mesmo público, ressaltando suas tradições cotidianas que não são atingidas pela produção da indústria 
cultural de massa. O consumo oblíquo (isto é, a atitude de não levar a sério tal produção), a apropriação conforme os seus habitus, a existência de uma minoria resistente e resiliente em busca de outro acesso aos bens culturais no interior das classes populares são todos eles fenômenos que se opõem à produção de massa voltada para o lucro imediato.

E são esses universitários — que tiveram parte de suas carreiras voltadas para o ensino aberto de adultos das classes populares, nas associações educacionais de trabalhadores ou nas open universities inglesas - que inspiraram os chamados "cultural studies" que depois se difundiram no mundo anglo-saxônico e para além dele. E.P. Thompson, Raymond Williams, Richard Hoggart estiveram ligados a estas instituições universitárias de adultos, de formação continuada. E muito de sua formulação acadêmica teve a influência do contato renovado com essa minoria resistente das classes populares inglesas. Alguns dos historiadores culturais, como Roger Chartier, se inspiraram diretamente em Hoggart para desenvolver a noção de apropriação cultural na circulação de ideias entre grupos e classes sociais. E não foi à toa que Bourdieu e Passeron promoveram desde $1970 \mathrm{a}$ tradução para o francês de The Uses of Literacy como uma obra inspiradora para as pesquisas que desenvolveram em torno da sociologia da educação e da cultura. Além disso, como ambos se consideravam trânsfugas de classe como Hoggart, apoiaram-se na sinceridade sistemática deste último usado como método para desenvolver partes de suas próprias teorias. (E Bourdieu, ao final de sua vida, pratica a sinceridade sistemática de Hoggart em seu livro póstumo Elementos para uma autoanálise).

Mas nem só de acadêmicos ingleses envolvidos com as classes populares estavam constituídos os quadros das open universities. Havia também a entrada de intelectuais exilados do nazismo, como Karl Polanyi e Norbert Elias, que passaram por aqueles postos universitários menos estáveis a caminho de outras vagas. E é com o pensamento aguçado pela experiência de "ovo da serpente" que havia vivido na Alemanha, que Elias vem colocar uma restrição à possível generalização da hipótese de Thompson sobre a força transformadora ancorada nas tradições. Não foi à toa que Elias se interessou pelo que estava encontrando em campo o seu aluno John Scotson na pequena cidade industrial por eles chamada ironicamente de Winston Parva. Ali, uma parcela de trabalhadores, com antiguidade na pequena cidade e na sua vida associativa, começou a estigmatizar, através das fofocas e dos rumores, moradores de novos conjuntos habitacionais, também trabalhadores ingleses, transferidos de Londres no pósguerra em consequência do bombardeio de suas antigas casas.

Sem outras diferenças entre si, étnicas ou de classe, além da antiguidade no lugar, Elias mostra como em certas circunstâncias a antiguidade ou a 
tradição pode dar lugar não à construção de um instrumental de resistência que sirva para a libertação de muitos, do maior número possível, mas ao contrário, que pode propiciar o fechamento e a aristocratização do pequeno grupo. Um ambiente, em plena Inglaterra de meados dos anos 1950, que parece evocar, na pequena cidade industrial, aquele encontrado na soturna aldeia rural austríaca do filme A Fita Branca. Uma advertência de Elias ao otimismo implícito nos estudos de comunidade sobre a classe trabalhadora inglesa, em que nunca está ausente a solidariedade de classe. E uma autoadvertência ao otimismo contido nas suas próprias análises evolucionárias do processo de civilização.

De fato, há que se estar atento às especificidades históricas de cada grupo social, de cada trajetória de indivíduos representativos de seus grupos sociais de origem. Há diferenças entre os operários do açúcar e os operários e as operárias têxteis, todos eles de Pernambuco. Como há diferenças entre a trajetória de Garrincha e a de Pelé, embora ambos sejam originários de grupos das classes populares.

\section{A tecelagem de uma memória coletiva}

Ao retornar aos meus objetos de pesquisa, vou começar pelo fim: enquanto a fábrica têxtil que originou a cidade de Paulista fechou definitivamente suas portas em meados dos anos 1990, a usina de açúcar na qual estudei continua funcionando bem, sendo uma das mais sólidas do estado de Pernambuco, sobrevivendo à falência de muitas de suas similares desde o início da década dos 90. No entanto, com os operários e as operárias de Paulista pudemos construir uma relação que tem durado desde 1976 até os dias de hoje, enquanto a comunicação com os operários da usina pouco durou. O território da usina e sua vila operária continuaram sendo o monopólio do poder da empresa. Já a cidade de Paulista havia transbordado de sua vila operária original, com a perda do monopólio da companhia sobre o território da cidade tendo se consolidado na segunda metade dos anos 1960. Quando lá estivemos pela primeira vez em 1976, a maior parte das casas da vila operária havia sido revertida às famílias operárias por força de indenizações trabalhistas, e podíamos visitá-las sem interferência da administração da companhia.

Como já dissemos, os operários e as operárias têxteis de Pernambuco apresentam uma maior sensibilidade à acumulação de uma memória social que sirva de capital para a transformação, mais do que seus colegas operários das usinas de açúcar. Para isso, cremos que haja uma série de razões. 
Algumas são da ordem de uma morfologia social. A concentração de famílias operárias na cidade de Paulista com vistas ao recrutamento de trabalhadores para suas fábricas, promovida pela companhia têxtil fundadora da cidade, deu uma significativa grandeza à sua vila operária, superior às dimensões habituais. Com uma vila de 6 mil casas em 1950 e com uma força de trabalho, quando no seu auge, em torno de 15 mil trabalhadores, a Companhia de Tecidos Paulista era uma das maiores fábricas em escala internacional (perto de uma CSN em Volta Redonda). A fábrica de Amoskeag, em Manchester, New Hampshire, EUA, considerada a maior do mundo no setor têxtil, teve, no auge, 17 mil trabalhadores em 1915 (segundo a historiadora Tamara Hareven).

O fato de a fábrica têxtil utilizar-se igualmente de trabalhadores masculinos e femininos traz importantes repercussões na formação de uma comunidade operária mais estável. Como mostram os trabalhos de Rosilene Alvim, a fome de operárias para postos de trabalho na fiação e na tecelagem por parte da fábrica repercutiu no recrutamento de famílias numerosas. O atendimento a tal aliciamento era conveniente especialmente para as famílias camponesas, com muitas filhas mulheres, composição que dificultava o sustento no campo. Além disso, essa necessidade de trabalhadoras mulheres implicava um recrutamento secundário de membros familiares por parte das unidades domésticas quando as operárias tinham filhos e novos membros eram requisitados para serviços na casa. Como os membros masculinos e os femininos podiam ser empregados pela fábrica, isto aumentava as possibilidades de as famílias continuarem a usufruir das casas da vila operária, em comparação com as usinas de açúcar onde só os homens trabalhavam.

Em períodos de crise da fábrica têxtil, provocando dispensas e desemprego, os homens, que têm um projeto permanente voltado para o trabalho, saíam da cidade em busca de emprego. Já as mulheres, voltadas para a família e de hábito incorporando projetos temporários de emprego, permaneciam nas casas. Quando havia uma volta cíclica de expansão e os empregos retornavam, as mulheres estavam disponíveis para o trabalho, enquanto os homens não regressavam. Há também aquelas operárias que encarnam as provedoras da família e que permanecem celibatárias pelo menos até a sua saída da fábrica. Tais práticas repercutem numa estabilidade maior ao longo do tempo do grupo operário e em maiores chances de permanência das várias gerações de uma mesma família na vila operária e na cidade.

Por outro lado, o próprio tamanho das instalações fabris e da vila operária fez a companhia industrial reivindicar o estatuto de município, desmembrando-se de Olinda em 1935. Inicialmente sob o controle da companhia, a administração local teve seu estatuto público reivindicado pelo governador 
do estado desde o final dos anos 30 . O choque entre uma concepção de cidade-oikos (uma cidade-empresa) e outra, de cidade diversificada, defendida por setores diferentes, animou a disputa política local desde então.

O caso do grupo operário de Paulista tem assim todas as características de formação do que Elias chama, estendendo Weber, de um carisma de grupo. Pois de fato a coesão dos grupos operários, geralmente pressuposta no efeito-teoria da consciência de classe possível, é algo a ser construído e demonstrado. É de se perguntar mais frequentemente como alguns desses grupos alcançam uma coesão e um estado de mobilização diante de tantas condições e circunstâncias desfavoráveis. Assim, por exemplo, Maurice Halbwachs considera a classe operária, na sua versão de uma alienação proletária, como uma classe voltada para a matéria e isolada da sociedade. Mas também podemos considerar o próprio laboratório secreto da fábrica como uma microssociedade com suas hierarquias, divisões e solidariedades.

Os operários do açúcar com suas diferenciações e autoclassificações internas polarizadas pelas categorias de arte e de artista, características dos operários de manutenção, acabam construindo um código interno que se difunde a todos os trabalhadores da usina, o código da arte, que reforça a coesão operária em face dos chefes da hierarquia interna, deslegitimados por não serem produtores diretos da matéria. É como se uma face da dupla verdade do trabalho proposta por Bourdieu - o gosto pelo trabalho bemfeito e o orgulho da profissão - pregasse uma peça na outra face, a verdade da exploração do trabalho, deslegitimando-a. Mas se aos operários do açúcar falta uma historicidade ativa que impulsione sua mobilização para a diminuição daquela exploração, isto não esteve ausente da trajetória dos operários de Paulista.

Dentre as características prescritivas das histórias individuais que deveriam seguir um padrão para se encaixarem na história comum concebida pelo grupo operário de Paulista há as seguintes: 1. O aliciamento de famílias numerosas de trabalhadores e trabalhadoras, em geral das áreas rurais, para o trabalho na fábrica; 2 . O ritual de apresentação dos membros das novas famílias recrutadas, dispostos em fila, para serem apreciados pelo patrão em carne e osso, na varanda da casa-grande. Tratava-se do singular desempenho de uma teatralização industrial da dominação personalizada tradicional; 3. O trabalho para todos, inclusive das crianças e dos velhos, dentro da fábrica ou em setores externos; 4. A concessão de roçados aos velhos pais de família camponeses nas proximidades da vila operária ou de lotes de terra em áreas mais distantes para famílias camponesas, conjugada com a canalização da produção agrícola dali obtida para uma feira com preços administrados pela companhia. Com isso, os salários mais baixos que 
a CTP pagava aos seus operários eram compensados por um custo de vida também mais baixo; 5 . O controle da vida social da cidade, com a promoção de banda de música, clubes de futebol, folguedos, abertura dos jardins da casa-grande nas tardes dos domingos para a população, mas também com a atuação de um corpo de vigias da companhia por toda a cidade e no interior do município; 6 . O controle da vida religiosa, com a promoção da Igreja católica e o desfavorecimento dos cultos evangélicos, assim como a tendência ao controle da vida política local. (É interessante assinalar que a Juventude Operária Católica, apoiada inicialmente pela companhia nos anos 40 e metade dos 50, passa a ser nos anos 60 uma das principais fontes de recrutamento sindical).

Grande parte destes itens dava uma legitimidade à dominação patronal diante da população local. Este equilíbrio, que favorecia a legitimidade da companhia, foi ameaçado pelas tentativas de implantação das leis sociais localmente, o que provocava fortes reações da companhia, produzindo acontecimentos que se incorporaram à memória da população operária.

Essa forte ligação entre memória individual e memória histórica, que passa pela memória do próprio grupo e que se manifesta nas características da forma de dominação estabelecida localmente, também se atualiza nas peripécias das reivindicações por melhores condições de vida, pela aplicação dos direitos sociais e por uma maior autonomia da cidade em relação ao poder econômico. Ainda era lembrada pelos mais velhos a luta de Roberto Marques, chamado pelo patrão de Roberto do Diabo, o primeiro sindicalista de 1932 que lutou pela aplicação da lei da jornada de 8 horas, e que saiu da cidade com o sindicato fechado. A este episódio era associada uma versão do mito do fim dos galos de briga do Coronel Frederico, que teria mandado matá-los após ser acordado em algum dia dos anos 30 com o canto anunciador de cocorocó-sindicato. Também era lembrada a saída teatral da cidade do último coronel, o Comendador Arthur, depois que foi impedido de entrar em uma de suas fábricas pelo piquete dos operários na greve de 1963. No interior daquela fábrica localizava-se a casa de banhos no antigo sítio dos galos, onde aquele patrão exercitava seu banho cotidiano matinal.

Nosso trabalho foi orientado inicialmente pela interpretação dos relatos e das interpretações dos trabalhadores quanto à sua história, ressaltada espontaneamente. Mas os fatos que apontavam tal confluência de memórias individuais e históricas, embora contadas oralmente entre os operários na forma de uma memória subterrânea, para usar o termo de Michael Pollak, também deveriam ter deixado marcas nos registros escritos. Esse corpus de relatos nos orientou subsequentemente na procura de uma documentação que correspondesse às informações e às representações contidas na memória 
dos trabalhadores; em coleções de jornais, em relatórios anuais aos acionistas da companhia publicados na imprensa; em documentos governamentais e em arquivos sindicais - cada fonte de informações tendo que sofrer um processo de interpretação pertinente.

\section{A demanda pela objetivação da memória no campo revisitado}

Ao retornarmos ao campo perto de trinta anos depois de nossa primeira ida, a situação encontrada era a finalização de um processo anunciado, comum a outras fábricas constituídas no início do século XX no Brasil, processo este dominado pelo declínio.

Quando terminamos, em 1983, a fase mais intensa e prolongada de nossa pesquisa com os operários de Paulista, parecia-nos que estavam dadas condições favoráveis para que a história e a memória daquele grupo social, que lhe conferiam identidade, fossem transmitidas às gerações seguintes. Ali estava um grupo formado por relações densas de parentesco e vizinhança, com uma história cheia de peripécias envolvendo não somente a política e a vida social locais, mas atingindo as escalas da política estadual e nacional, com uma trajetória que finalizava parcialmente vitoriosa através do acesso à propriedade das casas da vila operária por efeito de indenização trabalhista. E havia se constituído no município, em terras vendidas pela companhia, um distrito industrial com novas fábricas, que mantinham as expectativas de emprego das novas gerações operárias. No entanto, a partir de meados dos anos 80, transformaram-se as próprias condições do modo de geração dos descendentes daquele grupo operário. Declinaram as chances de emprego industrial estável para as novas gerações; aumentaram os esforços das famílias numa escolarização mais prolongada de seus filhos sem que isto redundasse em melhores empregos; a população da cidade mudou sua composição com a chegada em massa de novos habitantes provenientes do Recife para ocuparem os novos conjuntos habitacionais.

É neste contexto que aparecem fortes demandas pela recuperação e a sistematização da memória social da cidade por parte de agentes significativos do espaço público local. E em que a volta dos pesquisadores ao local sobre o qual produziram teses e livros não passa despercebida a tais agentes; a própria condição de pesquisador-coletor de dados é vista de forma diferente e transformada em pesquisador testemunha da história, em sistematizador e colaborador na divulgação da história local. Já Raymond Firth, em 1954, após seu reestudo nos dois anos anteriores da Tikopia que ele havia pesquisado em 1928 e 1929, procura refletir sobre os estudos bissincrônicos 
feitos por alguns antropólogos numa sequência espaçada de visitas a um mesmo campo com a finalidade de captar a mudança social. No seu caso de revisita com o antropólogo canadense James Spillius, eles acabaram tendo um papel de mediadores entre o grupo estudado e as autoridades em função de um período de fome e escassez. No nosso caso, havia uma fome de reconstituição da memória coletiva do grupo, ameaçada de ser relegada ao silêncio e ao esquecimento.

Em diversas áreas industriais antigas, como as ex-vilas operárias de fábricas têxteis (e de outros setores industriais) na área metropolitana de Recife, movimentos sociais locais esboçam lutas por maior participação dos moradores na administração local, procurando minorar os impactos que desfiguram o formato tradicional desses bairros, como, por exemplo, no caso extremo da conversão de estradas locais em complexos de autoestradas, destruindo, devido ao seu traçado avaliado em termos econômicos estritos, a paisagem usual, o que aconteceu na própria cidade de Paulista. As transformações nessas antigas cidades industriais se dão no sentido de uma dispersão de sua força de trabalho, antes concentrada localmente, por toda a região metropolitana, aumentando os fluxos de deslocamento de trabalhadores. Nessas áreas, o patrimônio histórico potencial representado pelas vilas segue sendo descaracterizado e transformado, sem constituir-se num recurso de políticas públicas voltadas para a história e a cultura locais. Antigos terrenos e galpões desativados tornam-se um passivo ambiental sem perspectivas de compensação.

Por sinal, a nova noção de "direitos difusos" pode aplicar-se tanto à penalização e à correção de danos ambientais (neste caso, terrenos baldios e ruínas industriais, eventualmente contaminados) quanto à promoção da patrimonialização de um espaço material significativo para a memória social como uma forma de compensação ambiental. Setores das sociedades civis destas cidades não desconhecem esses novos direitos, numa tendência que uma equipe de pesquisadoras que eu tive a felicidade de coordenar com Shelton Sandy Davis caracterizou, em termos gerais, como a ambientalização dos conflitos sociais.

O interesse do sindicato dos tecelões de Paulista pela sistematização e divulgação da história local, ressaltando suas tradições operárias, foi o principal fator através do qual nossa nova pesquisa na localidade, nos anos 2000, acabou desembocando em atividades de busca e coleta de registros visuais e sonoros que pudessem ser divulgados publicamente. Os diretores sindicais fazem parte de uma geração que trabalhou nas fábricas do distrito industrial, filiais de fábricas do Sul e multinacionais da era Sudene. Eles assumiram, no fim dos anos 80 , sob os ventos do novo sindicalismo com 
uma chapa de denominação autoirônica: os papa-pelos (em referência às partículas de algodão desprendidas nas fábricas). Esse distrito industrial, por sua vez, sofreu também entre os anos 90 e 2000 um processo de desindustrialização. Os mentores da associatividade inicial destes sindicalistas foram alguns de nossos antigos pesquisados-chave, que se tornaram personagens do filme que acabamos fazendo. Para os novos sindicalistas, de resto seguindo a tradição do senso comum local, a história a ser privilegiada é a da antiga fábrica que criou a cidade, a CTP das Casas Pernambucanas.

Ao desencadear-se a feitura de um documentário sobre a memória dos ex-operários sobre sua trajetória e vida cotidiana no "tempo da companhia", foram-se acumulando materiais visuais, novos personagens e eventos voltados para uma objetivação desta memória social. No dia $1^{\circ}$. de maio de 2005, participamos da organização de um evento na sede do sindicato denominado "Memória dos Tecelões", quando foram projetadas antigas fotos da cidade e foi constituída uma mesa com ex-operários, que falaram sobre suas experiências na fábrica e na cidade. Seguiu-se a abertura de novos depoimentos por parte de membros do público presente. Com isso, deu-se a partida pública para um trabalho em conjunto com uma rede de ex-pesquisados dos anos 70 e de sindicalistas atuais, que vinha sendo planejado em conversas e reuniões anteriores. Tal evento incentivou a troca de informações e pôs o foco na viabilidade de iniciativas de articulação em torno da história local.

Estava presente um grupo de jovens de formação universitária e professores secundários moradores na cidade, alguns deles filhos e netos de ex-operários e funcionários da companhia, também interessados na memória local. No final de 2005, eles constituíram o "movimento pró-museu de Paulista", diante dos rumores da venda da casa-grande e seus jardins por parte dos proprietários da CTP para uma grande empresa nacional de lojas de departamento, o que acarretaria a destruição da casa-grande e do "jardim dos coronéis". O movimento defende o patrimônio material e imaterial do município, mas prioritariamente a casa-grande e seu jardim. É interessante que grupos da sociedade civil local tenham se fixado na casa-grande patronal como monumento da memória da cidade e das famílias operárias que a construíram (e que estão na origem de muitas das famílias atuais). Na falta da possibilidade de aproveitamento para fins públicos das ruínas das duas fábricas de Paulista, e na falta de lugares públicos histórica e simbolicamente significativos nos múltiplos arruados do conjunto arquitetônico da grande vila operária, a casa-grande passa novamente a se destacar.

Para a atual direção da CTP, a venda do terreno da casa-grande e de seus jardins para uma loja de departamentos seria uma de suas maiores transações com ativos dentre os muitos de que ainda dispõe. Esta iniciativa 
não contava em seus planos com a mobilização de setores do espaço público de Paulista, como o sindicato dos tecelões e os jovens professores do movimento pró-Museu. Em 2007 foi constituído um sítio na internet deste movimento "pró-museu", e foi reivindicado o tombamento da área disputada junto ao Conselho Estadual de Cultura. Para os ex-trabalhadores da cidade, a casa-grande está associada ao "tempo dos coronéis", com suas grandezas e conflitos, desde sua frequentação como lazer concedido pelo patrão aos seus operários, e de visitas e fotos abaixo do busto do Coronel Frederico, até os episódios da greve de 1963 e do cerco à casa-grande através do corte de abastecimento de água. Após um longo período de tramitação no Conselho Estadual de Cultura e de discussões sobre a prioridade ou não deste tombamento industrial, finalmente tal Conselho deu um parecer favorável a esta patrimonialização. Resta saber como se processarão as negociações com o que resta da CTP, seu poder econômico tendo força junto ao poder municipal; e se haverá vontade deste último de estimular a organização do centro cultural pretendido, e como se darão ali as disputas em torno da memória. De qualquer forma, a perspectiva do apagamento da memória deste grupo social não se confirma facilmente, com a reconversão de antigos grupos sociais para novas disputas e com o aparecimento de outros agentes sociais (com suas subsequentes gerações) e a apropriação de instrumentos de políticas públicas e novos direitos sociais.

O filme Tecido Memória registra assim, através de outra linguagem, esse novo período de campo após o intervalo de trinta anos, através dos instrumentos da antropologia visual que nossas (e nossos) colegas especialistas desta área vinham aperfeiçoando. A etnografia de longa duração pode agora conter um documento construído com a participação explícita dos pesquisados - editados e mostrados publicamente em carne, osso e palavra; um documento a ser apropriado de forma mais favorável pelo próprio grupo retratado e seus descendentes.

Se o reverso dos antropological blues pode ser o entusiasmo da observação participante, da comunhão com os pesquisados, de estar lá, na máquina como operário, à feição de Donald Roy ou Burawoy, para depois praticar o distanciamento na análise, tal entusiasmo talvez possa ser alcançado com uma objetivação participante que, além de analisar, proporcione a devolução ao grupo de instrumentos de emoção e reflexão. Os praticantes de uma etnografia de longa duração com grupos de trabalhadores, como Huw Beynon, Michel Pialoux, Abdelmalek Sayad, Robert Cabannes, William Wilson, entre outros, alcançaram isto com seus escritos. O gosto pelas consequências da prática antropológica de muitos colegas de métier — tais como o apoio às populações indígenas e às populações tradicionais, às minorias 
estigmatizadas, às populações camponesas ameaçadas, aos trabalhadores em situação de injustiça, e aos movimentos que defendem o patrimônio cultural, ambiental, histórico, material e imaterial - algo deste mesmo gosto pode também estar presente na devolução de um artefato numa linguagem estética que consiga encenar uma palavra coletiva, mas com os indivíduos aparecendo, se reconhecendo no produto e se emocionando.

O filme Tecido Memória termina com as palavras do ex-tecelão e exsindicalista de base Marcelo Castanha que comenta, no final da entrevista filmada, quando a câmera já estava para ser desligada:

Olha, até hoje eu tenho saudade da fábrica. Tenho saudade da fábrica. Se tivesse possibilidade, eu ainda ia trabalhar. A gente sente saudade da convivência com os companheiros. Um não podia ver o outro triste, todo mundo era colega, todo mundo brincava. Hoje em dia, se eu pudesse, se tivesse possibilidade... nem 12 nem 30 não, mas umas seis máquinas eu ainda tocava. Se pudesse, eu ainda ia trabalhar, só porque a vida do trabalhador é boa, é sofrida, mas é boa.

Estas palavras aludem ao mesmo tempo à sua aposentadoria individual e ao processo coletivo de fechamento de fábricas, como se fosse a despedida de certa classe operária. No entanto, as lições de vida social que deixa esta experiência secular permanecem como instrumentos para as novas classes trabalhadoras. E deixa ensinamentos inesperados para a sobrevivência diante de novas formas de dominação no presente e no futuro, como pode indicar a metáfora dos "jardins murados" usada por Hermano Vianna, em artigo recente em que compara as regras do jogo de uma determinada companhia de redes sociais na internet, o Facebook, com um "condomínio cercado por muros e seguranças, com serviços 'públicos' próprios e onde todas as casas são propriedade de uma única empresa e não de quem mora nelas". Em suma, digo eu, de vilas operárias de fábricas virtuais. Ou ainda, a experiência de resistência da classe operária concentrada deixa legados para o estudo e para o respeito às profissões humildes diversificadas que proliferam no novo mundo globalizado e que já Everett Hughes acenava, nos anos 50, como alvo principal do drama social do trabalho.

Se a memória coletiva é, como vimos, um instrumento para a transformação social, também certas grandes transformações estimulam uma demanda premente por uma memória objetivada e transmissível. Além disso, a memória, ela própria, se transforma ao longo do tempo de acordo com as necessidades e as disputas do presente, podendo tornar-se, em certas circunstâncias, um elemento de coesão ou um campo de novos conflitos sociais. É importante assinalar que as especificidades históricas dos grupos 
de trabalhadores como os aqui apresentados podem ser estratégicas para o avanço do conhecimento ao chamarem a atenção para certas configurações de vontades coletivas e de imponderáveis da vida real na escala de desenvolvimentos históricos imprevistos. Ao objetivar uma memória em disputa, inclusive no pensamento dos indivíduos, e conseguir formas de transmitir tal objetivação aos grupos estudados, a antropologia social pode participar na elaboração do mundo e contribuir para um sentimento de libertação de dominações incorporadas.

Uma pequena palavra final. Gostaria de registrar aqui a generosidade de Luiz Fernando Dias Duarte de considerar que seu momento de prestar este concurso deveria ser o seguinte. E gostaria de homenagear duas colegas que, caso este concurso pudesse ter sido realizado alguns anos antes, por motivos diferentes, deveriam estar aqui no meu lugar: Lygia Sigaud e Giralda Seyferth.

José Sergio Leite Lopes é professor titular do Programa de Pós-Graduação em Antropologia Social, Museu Nacional, UFRJ. E-mail: <jsergiollopes@gmail.com>

\section{Nota}

*Conferência proferida em 24 de agosto de 2011 no Programa de Pós-Graduação em Antropologia Social, Museu Nacional, UFRJ, por ocasião do concurso para professor titular da mesma instituição. No texto original, escrito para ser lido, não havia referências bibliográficas. Elas foram inseridas para que o leitor tenha acesso às fontes que serviram de base ao que foi mencionado no texto. 


\section{Referências bibliográficas}

ALVIM, Rosilene, 1983. "Artesanato, tradição e mudança social: um estudo a partir da arte do ouro de Juazeiro do Norte". In: O artesão tradicional e a sociedade contemporânea. Rio de Janeiro: FUNARTE. . 1997. A sedução da cidade; os operários camponeses da fábrica dos Lundgren. Rio de Janeiro: Graphia. . \& LEITE LOPES, José Sergio. 1990. "Famílias operárias, famílias de operárias". Revista Brasileira de Ciências Sociais, 14(5):1-17.

BEYNON, Huw. 1985 [1973]. Working for ford. Harmondsworth: Penguin. . \& AUSTRIN, Terry. 1996. Masters and servants: class and patronage in the making of a labour organisation. Rivers: Oram.

BOURDIEU, Pierre. 1963. Travail et travailleurs en Algérie. Paris, La Haye: Mouton \& Co. 2001. Meditações pascalianas. Rio de Janeiro: Bertrand Brasil. . 2005. Esboço de autoanálise. São Paulo: Companhia das Letras.

BURAWOY, Michael. 2003. "Revisits. An outline of a theory of reflexive ethnography". The American Sociological Review, 68:645-679.

CABANNES, Robert. 2002. Travail, famille, mondialisation: récits de la vie ouvrière, São Paulo, Brésil. Paris: Karthala.

DENNIS, Norman; HENRIQUES, Fernando; SLAUGHTER, Clifford. 1969 [1956]. Coal is our life; an analysis of a Yorkshire mining community. London: Tavistock Publications.

DURKHEIM, Emile \& MAUSS, Marcel. 1969 [1903]. "De quelques formes primitives de classification. Contribution à l'étude des représentations collectives". In: Oeuvres. Paris: Minuit (org. Victor Karady).
ELIAS, Norbert \& SCOTSON, John L. 1994 [1965]. The established and the outsiders. A sociological enquiry into community problems. London: Sage Publications [Ed. brasileira: Os estabelecidos e os outsiders: sociologia das relações de poder a partir de uma pequena comunidade. Rio de Janeiro: Jorge Zahar, 2000].

EVANS-PRITCHARD，E .E. 1978[1940]. Os Nuer. Uma descrição do modo de subsistência e das instituições políticas de um povo nilota. São Paulo: Perspectiva.

FRENCH, John D. 2004. Drowning in laws: labor law and brazilian political culture. North Carolina: University of North Carolina Press. [Ed. bras. Afogados em leis. A CLT e a cultura política dos trabalhadores brasileiros. São Paulo: Fundação Perseu Abramo, 2001].

FRANKENBERG, Ronald. 1966. Communities in Britain; social life in town and country. Harmondsworth: Penguin Books.

FIRTH, Raymond. 1964. "Social organization and social change [1954]", "Some principles of social organization [1955]". In: Essays in social organization and values. London: Athlone. pp. 30-87.

GOFFMAN, Erving. 1971 [1961]. Asylums. Essays on the social situation of mental pacients and other inmates. Harmondsworth: Penguin Books.

HAREVEN, Tamara. 1982. Family time \& industrial time. London: Cambridge University Press.

HOGGART, Richard. 1969 [1957]. The uses of literacy. Aspects of workingclass life with special reference to publications and entertainements. Harmondsworth: Penguin Books. 
HUGUES, Everett. 1971. The sociological eye. Chicago: Aldine-Atherton.

LEITE LOPES, José Sergio. 1976. O vapor do diabo: o trabalho dos operários do açúcar. Rio de Janeiro: Paz e Terra. . 1988. A tecelagem dos conflitos de classe na "cidade das chaminés". São Paulo-Brasília: Marco Zero/Ed. da UnB.

LEITE LOPES, Sergio; ALVIM, Rosilene e BRANDÃO, Celso. 2008. Tecido memória. Documentário longa metragem em DVD (70 min). Rio de Janeiro: Museu Nacional.

LEITE LOPES et alli. 2004. A ambientalização dos conflitos sociais; participação e controle público da poluição industrial. Rio de Janeiro: Relume-Dumará (coleção Antropologia da Política).

LEVI-STRAUSS, Claude. 1962. La pensée Sauvage. Paris: Plon.

LINHART, Robert. 1978. L'Établi. Paris: Minuit [Ed. bras. Greve na Fábrica. Rio de Janeiro: Paz e Terra, 1980].

MARX, Karl. 1984 [1867] O Capital. Crítica da economia política. São Paulo: Editora Abril.

MINTZ, Sidney. 1960. Worker in the cane. A puerto rican life history. New Haven: Yale University Press. 2003. O Poder amargo do açúcar. Produtores escravizados, consumidores proletarizados. Recife: Editora Universitária UFPE.

MOORE Jr., Barrington. 1979. Injustice. The social basis of obedience and rebellion. London: MacMillan.

NASH, Manning. 1958. Machine age maya. The industrialization of a guatemalan community. The American Anthropological Association, Memoir n. 87.

PALMEIRA, Moacir. 1976. "Morar: a lógica da plantation tradicional". Actes $d u$ XLII Congrès International des Américanistes, I:305-315.

PALMEIRA et alli. 1976. "Emprego e mudança sócio-econômica no Nordeste (projeto de pesquisa)". Anuário Antropológico 1976.

PIALOUX, Michel. 2011. "Avant-propos". In: Christian Corouge \& Michel Pialoux (orgs.), Résister à la chaîne. Dialogue entre un ouvrier de Peugeot et un sociologue. Marseille: Agone.

POLLAK, Michael. 1989. "Memória, esquecimento e silêncio". Estudos Históricos, 2(3):3-15.

POWDERMAKER, Hortense. 1962. Copper town, changing Africa. The human situation on the Rhodesian Copperbelt. New York: Harper Colophon Books, Harper \& Row Publishers. . 1962. Stranger and friend; the way of an anthropologist. New York: W. W. Norton \& Company.

ROY, Donald. 2006. Un sociologue à l'usine. Paris: La Découverte (org. J. M. Chapoulie).

SAHLINS, Marshall. 1988. "Cosmologias do capitalismo: o setor transpacífico do sistema mundial". Conferência apresentada à XVI Reunião Brasileira de Antropologia. Campinas, 27 a 30 de março de 1988 [cap. 13 de SAHLINS, M. Cultura na prática. Rio de Janeiro: Editora da UFRJ, 2004].

SAYAD, Abdelmalek. 1998. A imigração ou os paradoxos da alteridade. São Paulo: EdUSP.

SIGAUD, Lygia. 1980. "A nação dos homens: uma análise regional de ideologia", Anuário Antropológico 78.

THOMPSON, Edward P. 1968 [1963]. The making of the english working-class. Harmondsworth: Penguin Books. 1998. Costumes em comum. São Paulo: Companhia das Letras.

WARNER, W. Lloyd \& LOW, J. O. 1965 [1947]. The social system of the modern factory. The strike: a social analysis. New Haven and London: Yale University Press.

WEIL, Simone. 1951. La condition ouvrière. Paris: Gallimard [Ed. bras. WEIL, 
Simone. A condição operária e outros escritos sobre a opressão. Rio de Janeiro: Paz e Terra, 1979].

WILSOM, William Julius. 1997. When work disappears. The world of the new urban poor. New York: Vintage Books.

WOLF, Eric. 2003 [1959]. "Aspectos específicos dos sistemas de plantations no Novo Mundo: subculturas das comunidades e classes sociais". In: Bela Feldman Bianco \& Gustavo Lins Ribeiro (orgs.), Antropologia e poder; contribuições de Eric Wolf. Brasília: EdUnB.

WOLF, Eric e MINTZ, Sidney. 2003 [1957]. "Fazendas e plantações na mesoAmérica e nas Antilhas". In: Sidney Mintz. O poder amargo do açúcar. Produtores escravizados, consumidores proletarizados. Recife: Editora Universitária UFPE.

YOUNG, Michael \& WILLMOTT, Peter. 1962. Family and kinship in East London. Harmondsworth: Penguin Books. 


\section{Resumo}

O artigo, apresentado anteriormente como conferência proferida em concurso, trata dos usos da antropologia social do trabalho no momento em que grande número de grupos de trabalhadores, numa escala internacional, é atravessado por transformações atingindo identidades coletivas anteriormente construídas. Argumenta-se que, se a memória coletiva é um instrumento para a transformação social, certas grandes transformações também estimulam a demanda premente por uma memória objetivada e transmissível. Além disso, a memória, ela própria, transforma-se ao longo do tempo de acordo com as necessidades e as disputas do presente, podendo tornar-se, em certas circunstâncias, um elemento de coesão ou, inversamente, um campo de novos conflitos sociais. Procura-se mostrar que as especificidades históricas dos grupos de trabalhadores como os apresentados no texto podem ser estratégicas para o avanço do conhecimento, ao se chamar a atenção para certas configurações de vontades coletivas e de imponderáveis da vida real na escala de desenvolvimentos históricos imprevistos. Por um lado, são comparados operários industriais do açúcar e, por outro, operários e operárias têxteis, segundo suas diferentes concepções de história. Mostra-se ainda como uma etnografia de longa duração com estes últimos operários e operárias pode ser apropriada por eles na construção de uma experiência de antropologia visual.

Palavras-chave Demanda social por memória coletiva objetivada, Hipótese da tradição transformadora, Desobreirização e história incorporada, Disputa pela memória e pelo patrimônio industrial.

\section{Abstract}

The present article was originally presented as part of a class taught for an employment interview. It deals with the uses of the social anthropology of work at a moment in which a large number of workers, on an international level, are being rocked by ttransformations of their previously constructed collective identities. I argue that collective memory is an instrument for social transformation and that certain large transformations stimulate the demand for an objectified and transmittable memory. I also argue that memory itself changes over time in accordance with the demands of present-day disputes, becoming in certain circumstances and cohesive element or inversely - an element that generates new social conflicts. I seek to show that the historical specificities of the workers' groups presented in the text can be understood as strategic for the advancement of knowledge by calling attention to certain configurations of collective will and of the impoderable facts of real life at the level of unforseen histgorical developments. Here I compare industrial workers in the sugar industry with textile workers, according to their differing conceptions of history. I show how an ethnography of the longue dureé of textile workers can be appropriated by the workers themsselves via the construction of a visual anthropological experiment.

Key words Social demand for objectified collective memory, Hypothesis of the transformative tradition, The decline of the working class and injcorporated history, Disputes over memory and industrial patrimony. 